\title{
Expanding Medical Marijuana Access in Canada: Considerations for the Rheumatologist
}
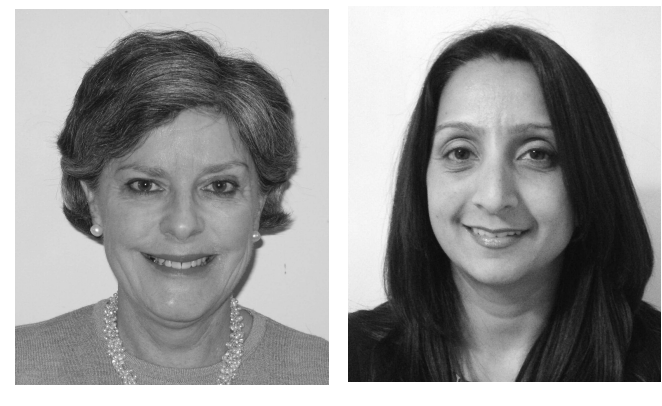

Similar to the enthusiasm for treatment of various ailments that greeted Nicotiana tabacum when brought to Europe from the New World 500 years ago, Cannabis sativa is now hailed as a possible treatment for a multiplicity of symptoms ${ }^{1}$. Embraced by physicians and the people, from commoners to the aristocracy, the enthusiasm for Nicotiana tabacum was questioned by a discerning few with concerns about the "indiscriminate use of the herb for all diseases in all age groups without specific measured prescriptions" 1 . Much like for tobacco many years ago, marijuana as the byproduct of Cannabis sativa, with significant financial incentives, requires careful appraisal regarding true therapeutic potential.

Cannabinoids are a diverse group of compounds, including in the animal/human system, phytocannabinoids derived from plants, and pharmaceutically prepared synthetocannabinoids. The herbal product is a complexity of over 400 molecules, thereby not allowing for direct comparison or interchangeability with synthetocannabinoids. While the latter are currently available as treatments for some conditions, we will focus on issues pertaining to the use of the phytocannabinoid marijuana (hereafter "herbal cannabis") in rheumatic diseases.

Therapeutic effects have been claimed for various conditions for centuries, but herbal cannabis largely fell into medical disfavor because of variable potency and short shelf life, and was superseded by synthetic analgesic agents that could be reliably dosed and studied ${ }^{2}$. As pain relief for rheumatic conditions is commonly cited as a reason for medicinal cannabis use, rheumatologists are increasingly caring for patients who are either selfmedicating or requesting advice regarding use. Legislators worldwide are currently debating the merits of expanding access to herbal cannabis for medicinal purposes. In some countries such as Canada, physicians will now be required to write a prescription for herbal cannabis. With increasing pressure from legislators, driven by public advocacy, there exists a discord between patient perception of a need and responsible clinical care.
Health Canada Regulations, Current and New

As Canada has been at the forefront of legalizing herbal cannabis for medicinal reasons, the timeline for access and current legal status for medicinal herbal cannabis use will be examined. In 2001, Health Canada adopted Marijuana Medical Access Regulations (MMAR), which recognized herbal cannabis as a treatment option for patients with various medical conditions, including severe pain from severe forms of arthritis, when the medical practitioner attested that "conventional treatment(s) have been tried or considered, and have been found to be ineffective or medically inappropriate." 3 Under these regulations, the medical practitioner provided the medical justification for an application, but not a prescription. Approval for possession of a specified amount of herbal cannabis was given by Health Canada officials.

The Government of Canada repealed the MMAR on March 31st 2014, and replaced these regulations with the Marijuana for Medical Purposes Regulations ${ }^{4}$. Under these new regulations, the medical practitioner will be entirely responsible for herbal cannabis prescriptions, similar to current prescribing practices for other drugs. A "medical document" stating daily dose and duration of use will be completed. These new regulations do not restrict use of herbal cannabis to any specific medical condition, nor do they require demonstration of failure of conventional treatments.

\section{The Challenges for Use of Herbal Cannabis as a Therapeutic Agent in Rheumatic Conditions}

Although also studied and used for effects beyond pain, such as anorexia, spasticity, and palliative care, "severe arthritis" is currently the most common reason that Canadians have authorization from Health Canada to possess medicinal herbal cannabis ${ }^{5}$. With the current expansion of medical cannabis use in Canada, rheumatologists will increasingly be asked to advise the healthcare community and patients on use of herbal cannabis.

As current rheumatic pain treatments are imperfect, both with regards to efficacy and side effect profile, it is under-

See Cannabis treatment of rheumatic diseases, page 146

Personal non-commercial use only. The Journal of Rheumatology Copyright (c) 2015. All rights reserved. 
standable that patients may explore other nontraditional treatment options ${ }^{6}$. With the knowledge that the endocannabinoid system is prevalent in the human body, cannabinoid ligands may have a therapeutic role for various ailments, including pain management, and therefore warrant further research in rheumatic diseases. Preclinical animal studies as well as studies of osteoarthritis and rheumatoid arthritis joints provide evidence that the endocannabinoid system is locally activated in response to pain stimuli in arthritis, and functions as a pain modulator ${ }^{7,8}$. As pain in rheumatic conditions is mediated by both nociceptive and neuropathic mechanisms, it is understandable that cannabinoids have a potential for therapeutic relief, thereby calling for more scientific study of the effects of herbal cannabis in rheumatic conditions.

The scientific research has, however, not yet translated into clinical application. Evidence-based medicine requires that a treatment be formally evaluated for efficacy and side effects pertaining to a specific disease before the medical community can accept widespread use outside a research setting. Herbal cannabis has not yet undergone this rigorous critical evaluation. Any information about the effects of cannabinoids in rheumatology practice is therefore based on anecdote, 2 small epidemiological studies, a handful of studies of cannabinoid molecules other than herbal cannabis, and extrapolation from studies of use in other conditions $\mathrm{s}^{9,10,11,12,13}$. Also lacking is information for dosing of herbal cannabis, other than patient report of use of various quantities. Therefore, the available evidence for efficacy of herbal cannabis represents the least convincing form of scientific evidence-based medicine. It follows that no current guideline has recommended the use of herbal cannabis for patients with rheumatic diseases.

Similarly, safety issues pertaining to short and longterm effects have never been formally studied in persons with rheumatic conditions ${ }^{14}$. Although some information regarding safety may be gleaned from studies of persons using marijuana for recreational purposes, this information may not be applicable to rheumatology patients with other comorbidities or concomitant medication use. Safety issues extend from the immediate risks of impaired cognition, psychomotor control, and memory, to the longterm risks for mental and pulmonary health. Potential concerns particularly applicable to patients with arthritis include aggravation of depression and risks associated with smoking, with other longterm risks for psychological health and dependence generic to all persons using herbal cannabis ${ }^{15}$.

As it is mostly believed that unauthorized users of cannabis for therapeutic reasons outweigh authorized users, the variability in concentration of specific molecules in illegally acquired cannabis is of concern. The mean concentrations of tetrahydrocannabinol (THC) in illicit marijuana have steadily increased globally, with levels almost doubling from about $9 \%$ in 2000 to $18 \%$ in a period of 5 years as noted in the Netherlands ${ }^{16}$. These higher concentrations of THC lead to higher serum levels with increased physical and psychoactive effects. It is hoped that regulated production of cannabis by licensed producers as set out in the Health Canada regulations will address these concerns and provide a more standardized product for patients medicating with herbal cannabis.

\section{Commentaries from Medical Regulatory Authorities and Other Bodies}

The Canadian Medical Association and the Federation of Medical Regulatory Authorities of Canada have opposed the change in regulations by Health Canada on grounds that evidence is insufficient to allow for prescription of herbal cannabis. Similar sentiments were stated in an editorial in the Canadian Medical Association Journal ${ }^{17}$. The Canadian Medical Protective Association, the largest medical mutual defense association in Canada, has cautioned physicians to only provide a prescription for herbal cannabis when conventional treatments have failed or are inappropriate and when they have the necessary clinical knowledge to engage in meaningful consent discussions with patients, and should inform the patient of the lack of information to date. Additionally, the risks and benefits of using medicinal herbal cannabis should be discussed and documented in the medical record. Health Canada has published a comprehensive document summarizing current evidence for therapeutic use of medical marijuana, highlighting the absence of evidence for efficacy or risk in patients with rheumatic diseases, and cautioning that smoking cannabis is not recommended, and activities requiring alertness may be impaired for up to $24 \mathrm{~h}$ following consumption ${ }^{18}$.

\section{The Voice of the Rheumatology Community Must Be Heard}

The basis of ethical and competent patient care is to ensure that any treatment has reliable efficacy that is not outweighed by risks. In consideration of use of herbal cannabis for rheumatic complaints, this first principle for patient care is lacking. Advice provided by healthcare professionals must also be based on sound knowledge derived from scientific study, clearly absent for herbal cannabis. Canadian rheumatologists have expressed a lack of confidence in their knowledge and ability to responsibly advise patients on the rational use of cannabinoid agents, including herbal cannabis, when recently polled ${ }^{19}$.

Public advocacy cannot and should not supersede scientific study. In our view, there is insufficient evidence to justify the widespread pressure on physicians to treat herbal cannabis differently from other prescription medications. In no other setting does any health regulatory authority require a health professional to prescribe a treatment that is not approved, has not been formally evaluated regarding dosing and effect, and that has not been adequately evaluated for

Personal non-commercial use only. The Journal of Rheumatology Copyright @ 2015 . All rights reserved 
either short or longterm safety in a chronic nonterminal condition.

By Health Canada estimates, the new regulations will lead to a tenfold increase in medical cannabis users with over 400,000 authorized users by 2024. The acceptance of these new regulations has transferred the gatekeeper role to physicians, a function previously held by government functionaries. In order to adhere to evidence-based medicine standards, we require immediate funding of high quality trials to examine dosing, efficacy, and risk of herbal cannabis in rheumatic conditions. If regulatory authorities expect physicians to carry the responsibility of prescribing herbal cannabis, similar to other prescription medications, they must adhere to usual standards for drug approval.

\section{ACKNOWLEDGMENT}

We acknowledge the contribution of Peter A. Ste-Marie, LL.B., to this article.

\footnotetext{
MARY-ANN FITZCHARLES, $\mathrm{MB}, \mathrm{ch}$ Alan Edwards Pain Management Unit, McGill University Health Center, Montreal, Quebec, Canada; and Division of Rheumatology, McGill University, Montreal, Quebec, Canada. SHAHIN JAMAL, MD, Division of Rheumatology, University of British Columbia, British Columbia, Canada.
}

Address correspondence to Dr. Mary-Ann Fitzcharles, Montreal General Hospital, 1650 Cedar Avenue, H3G 1A4, Montreal, Quebec, Canada. E-mail: mary-ann.fitzcharles@muhc.mcgill.ca Prepared on behalf of the Therapeutics Committee of the Canadian Rheumatology Association.

\section{REFERENCES}

1. Charlton A. Medicinal uses of tobacco in history. J R Soc Med 2004;97:292-6.

2. Kalant H. Medicinal use of cannabis: history and current status. Pain Res Manage 2001;6:80-91.

3. Government of Canada. Marihuana Medical Access Regulations. Minister of Justice. [Internet. Accessed August 3, 2014.] Available from: http://laws-lois.justice.gc.ca

4. Government of Canada. Marihuana for Medical Purposes Regulations. Minister of Justice. [Internet. Accessed August 3, 2014.] Available from: http://laws-lois.justice.gc.ca/eng/ regulations/SOR-2013-119/index.html\#
5. Office of the Information Commissioner of Canada, Information request (ATI 2013-00282) under the Access to Information Act, 2013.

6. Goldenberg, DL, Clauw DJ, Fitzcharles MA. New concepts in pain research and pain management of the rheumatic diseases. Semin Arthritis Rheum 2011;41:319-34.

7. Richardson D, Pearson RG, Kurian N, Latif ML, Garle MJ, Barrett DA, et al. Characterisation of the cannabinoid receptor system in synovial tissue and fluid in patients with osteoarthritis and rheumatoid arthritis. Arthritis Res Ther 2008;10:R43.

8. Schuelert N, McDougall JJ. Cannabinoid-mediated antinociception is enhanced in rat osteoarthritic knees. Arthritis Rheum 2008;58:145-53.

9. Ware MA, Fitzcharles MA, Joseph L, Shir Y. The effects of nabilone on sleep in fibromyalgia: results of a randomized controlled trial. Anesth Analg 2010;110:604-610.

10. Swift W, Gates P, Dillon P. Survey of Australians using cannabis for medical purposes. Harm Reduct J 2005;2:18.

11. Ware MA, Adams H, Guy GW. The medicinal use of cannabis in the UK: results of a nationwide survey. Int J Clin Pract 2005;59:291-5.

12. Blake DR, Robson P, Ho M, Jubb RW, McCabe CS. Preliminary assessment of the efficacy, tolerability and safety of a cannabis-based medicine (Sativex) in the treatment of pain caused by rheumatoid arthritis. Rheumatology 2006;45:50-2.

13. Skrabek RQ, Galimova L, Ethans K, Perry D. Nabilone for the treatment of pain in fibromyalgia. J Pain 2008;9:164-73.

14. Fitzcharles MA, McDougall J, Ste-Marie PA, Padjen I. Clinical implications for cannabinoid use in the rheumatic diseases: potential for help or harm? Arthritis Rheum 2012;64:2417-25.

15. Kalant H. Adverse effects of cannabis on health: an update of the literature since 1996. Prog Neuropsychopharmacol Biol Psychiatry 2004;28:849-63.

16. Mensinga TT, de Vries I, Kruidenier M, Hunault CC, van den Hengel-Koot IS, Fijen JW, et al. A double-blind, randomized, placebo-controlled, cross-over study on the pharmacokinetics and effects of cannabis. [Internet. Accessed June 4, 2014.] Available from: rivm.openrepository.com/rivm/bitstream/10029/ 7272/1/267002002.pdf

17. Fletcher J. Marijuana is not a prescription medicine. CMAJ 2013;185:369.

18. Health Canada, Information for Health Care Professionals Cannabis and the Cannabinoids, Health Canada Controlled Substances and Tobacco Directorate, Editor 2013.

19. Fitzcharles MA, Ste-Mariel PA, Clauw DJ, Jamal S, Karsh J, Leclercq S, et al. Rheumatologists lack confidence in knowledge of cannabinoids in the management of rheumatic conditions: a needs assessment of Canadian rheumatologists [abstract]. Arthritis Rheum 2013;65 Suppl:S49.

J Rheumatol 2015;42:143-5; doi:10.3899/jrheum.131514 